\title{
Evaluation of Nutrient Foramen in Adult Dry Human Femur
}

\author{
Sukriye Deniz Mutluay¹, Ahmet Kursad Acıkgoz², Memduha Gulhal Bozkır ${ }^{3}$ \\ ${ }^{1}$ Department of Midwifery, Cukurova University, Adana, Turkey. \\ ${ }^{2,3}$ Department of Anatomy, Cukurova University, Adana, Turkey.
}

\section{ABSTRACT}

\section{BACKGROUND}

Nutrient foramen is a large opening that transfers the arteries that supply the bone to the bone cavity. During surgical procedures, it is very important to have precise and complete information about the location of the foramina to determine whether the fracture line passes close to the nutrient foramina. The purpose of this study was to determine the number and position of the femoral nutrient foramina together with morphometric measurements.

\section{METHODS}

A total of 93 dry adult femurs with unknown sexes were examined in this study. The direction, location and the total number of nutrient foramina of the femur were investigated by using an anthropometer (Lafayette instrument, Indiana). Also, foraminal index was calculated.

\section{RESULTS}

The analysis revealed that $28(53.8 \%)$ of the femurs with a single nutrient foramen were on the right side and $22(53.7 \%)$ were on the left side, respectively. Femurs with double nutrient foramina were $23(44.2 \%)$ and $18(43.9 \%)$ on right and left sides, respectively. Femurs with triple nutrient foramina were $1(1.9 \%)$ and $1(2.4$ $\%)$ on right and left sides, respectively. The foraminal index of femurs was found as $(41,58 \%)$ and $(42,23 \%)$ on the right and left sides, respectively. The nutrient foramen was mostly $84(90.3 \%)$ located at the middle third of the femur.

\section{CONCLUSIONS}

The findings of this study provide information and details about nutrient foramen which have clinical importance, especially in surgical procedures like bone grafting and microsurgical vascularized bone transplantation.

\section{KEY WORDS}

Femur, Foraminal Index, Nutrient Artery, Nutrient Foramina
Corresponding Author: Dr. Sukriye Deniz Mutluay, Faculty of Health Sciences, Department of Midwifery, Cukurova University, Adana, Turkey. E-mail:dakman01@gmail.com

DOI: $10.14260 / j e m d s / 2021 / 723$

How to Cite This Article: Mutluay SD, Açıkgöz AK, Bozkır MG. Evaluation of nutrient foramen in adult dry human femur. J Evolution Med Dent Sci 2021;10(41):3566-3570, 10.14260/jemds/2021/723 DOI:

Submission 13-03-2021,

Peer Review 27-09-2021, Acceptance 04-10-2021, Published 11-10-2021.

Copyright (C) 2021 Sukriye Deniz Mutluay et al. This is an open access article distributed under Creative Commons Attribution License [Attribution 4.0 International (CC BY 4.0)] 


\section{BACKGROUND}

The femur is the longest and strongest bone of the human body. ${ }^{1}$ It consists of a diaphysis and two ends known as epiphyses. Typically, long bones and femur are supplied by four types of arterial systems; namely nutrial, epiphyseal, diaphyseal and periosteal arteries. The periosteal circulation; supplies blood to the structures such as the periosteum, the outer one-third of the underlying cortex and surrounding muscles. Whereas the medullary circulation, which originates from the nutrient artery supplies blood to the bone marrow and inner two-third of the bone cortex. . $^{3,4}$

Long bones have a large opening on the shaft named nutrient foramina. ${ }^{1}$ Nutrient foramen, which varies in number and location, is located on the surface of the femur called the linea aspera which are directed proximally along the bone; one usually near its proximal end and the second usually near its distal end. After the nutrient artery enters the foramen, it moves through the nutrient canal and opens into the marrow cavity. It forms many small vessels in the bone marrow sinusoids to nourish the cortex and spongy structure of the bone. ${ }^{5}$

Nutritional arteries provide blood supply and vascularization to long bones, which usually meet the need of bones during the growth phase and in the early stages of ossification.6,7 During the early phases of ossification, long bones receive about $80 \%$ of their blood flow from the nutritional arteries, and coronary arteries perform this task through the periosteum in case of lack of nutritional arteries. ${ }^{8,9}$ Bone nutrient supply leads to the survival of osteoblast and osteocyte cells in the bone, the role of which is important in bone vascularization and growth of long bones.

Typically in long bones, the vessel feeding the diaphysis moves away from the growing end of the bone. ${ }^{10}$ Previous studies have identified several variations regarding the location of the nutrient foramina in the lower extremity bones. ${ }^{11}$ Therefore, during the application of orthopaedic techniques such as bone resection and transplantation as well as vascularized bone microsurgery, it is an important necessity to understand the position of the foramina of the long bones and the blood supply of the bone with detailed information. $12,13,14,15$

This study was conducted to provide useful data for orthopaedic surgeons, anatomists and radiologists. For this purpose, morphometric measurements were made in the femoral bone to determine the location, number and foramen index of the femoral nutrient foramina. In addition, as there is genetic, racial, and ethnic diversity among humans, this study also intended to evaluate the nutrient foramina of our population's dry adult human femoral bone.

\section{METHODS}

The present study comprised an examination of included 93 dry adult femurs (52 right and 41 left sides). The age and sex of the femur bones used in the study were not known. Femur bones were obtained with the permission of the concerned head and authority of the Anatomy department, Faculty of Medicine, Çukurova University, between December 2020 and February of 2021.
The femurs were cleaned and labelled with site numbers. Only femur bones with good condition were included in the study. Bones that were deformed and damaged, bones with the callous formation and unossified bones were excluded from the study. Length of the bone was measured in $\mathrm{cm}$ using Lafayette anthropometer (Lafayette anthropometer is a mechanical sliding caliper which does not require calibration; a range of 0 to $60 \mathrm{~cm}$ in $0.1 \mathrm{~cm}$ increments which allows for measuring of shoulder width, long bone length and chest depth Model 01290, Lafayette instrument company, Indiana) and parameters estimated were measured using an elastic band and a digital vernier caliper that measured to $0.01 \mathrm{~mm}$ (TTI Vernier caliper, $0-200 \mathrm{~mm}$ ). The longitudinal axis of the bone was kept parallel to the longitudinal axis of the anthropometer. The proximal aspect of the caput femoris and the most distal aspect of the medial condyle of the femur were identified and marked to be measured; the grip ends of C-shaped arm branches of the sliding caliper, were rested against the forearms along the longitudinal axis of the bone. Pressure has been applied to the caliper's branches. The arm has been moved ends to the desired landmarks and the scale was read along the base of the caliper to the nearest centimetre.

The number of foramen nutricium in the femurs was recorded and measurements were taken in relation to the foramen nutricium. Measurements were taken as below.

1. (TLF) Total length of femur= the distance among the proximal aspect of the caput femoris and the most distal aspect of the medial condyle.

2. $(\mathrm{DNF})=$ the distance from the proximal end of the bone to the nutrient foramen.

3. Circumference of the nutrient foramen (foramen nutricium) (body of the femur) = the circumference of the femoral body was measured at the base of the largest foramen nutricium.

4. Transverse diameter of the femur at the location of nutrient foramina.

5. Anteroposterior diameter of the femur at the location of nutrient foramina.

6. Foraminal Index (FI): Hughes formula ${ }^{16}$ was used for calculating this index.

Foramen Index $(\mathrm{FI})=(\mathrm{DNF} / \mathrm{TLF}) \times 100$

The position of the foramina was divided into three types according to FI as follows -

- Type 1: $\mathrm{FI}<33.33$, the foramen was in the proximal third of the bone.

- Type 2: $33.33<$ FI < 66.66, the foramen was in the middle third of the bone.

- Type 3: FI > 66.66, the foramen was in the distal third of the bone.

\section{Statistical Analysis}

Statistical analysis of the data was performed by SPSS 21.0 programme. An independent sample t-test was used for descriptive statistics and bilateral differences, Spearman Pearson correlation test was used for correlation between measurements. Frequency and percentages were calculated. 


\section{RESULTS}

The following results were obtained. The mean values of 93 femoral (52 right and 41 left sides) bones and bilateral differences are shown in Table 1 . The mean total length of the femur on the right side was $42.77 \pm 2.99 \mathrm{~cm}$, while it was $43.50 \pm 3.25 \mathrm{~cm}$ on the left side. No, statistically significant differences between the right and left sides were shown in all measurements, including the total femur length $(\mathrm{P}>0.05)$. The correlations between all measurements on the femur are shown in Table 2.

\begin{tabular}{|c|c|c|c|c|c|c|c|c|c|}
\hline \multirow{2}{*}{ Measurement } & \multicolumn{4}{|c|}{ Right $(\mathrm{N}=52)$} & \multicolumn{4}{|c|}{ Left $(N=41)$} & \multirow[b]{2}{*}{$P$} \\
\hline & Mean & SD & Min & Max & Mean & SD & Min & Max & \\
\hline $\operatorname{TLF}(\mathrm{cm})$ & 42,77 & 2,99 & 36,60 & 50,00 & 43,50 & 3,25 & 37,60 & 54,40 & 0.265 \\
\hline TDNF $(\mathrm{cm})$ & 27,83 & 2,70 & 21,10 & 34,87 & 27,66 & 2,67 & 22,71 & 33,19 & 0.757 \\
\hline $\operatorname{APDNF}(\mathrm{cm})$ & 27,33 & 2,65 & 19,97 & 34,83 & 26,79 & 2,87 & 20,74 & 32,38 & 0.348 \\
\hline $\mathrm{DNF}(\mathrm{cm})$ & 17,73 & 3,64 & 12,60 & 26,20 & 18,36 & 4,80 & 11,53 & 37,30 & 0.470 \\
\hline $\mathrm{CNF}(\mathrm{cm})$ & 8,83 & 0,70 & 7,50 & 10,60 & 8,76 & 0,67 & 7,30 & 9,90 & 0.596 \\
\hline FI (\%) & 41,58 & 8,91 & 31,15 & 63,00 & 42,23 & 10,34 & 28,90 & 78,53 & 0.747 \\
\hline
\end{tabular}

\begin{tabular}{|c|c|c|c|c|c|c|c|}
\hline \multicolumn{2}{|c|}{$\begin{array}{c}\text { Measurements } \\
\text { (Parameters) }\end{array}$} & TDNF & APDNF & DNF & CNF & TLF & FI \\
\hline \multirow{2}{*}{ FI } & $\mathrm{r}$ & $-0.249^{*}$ & $0.245^{*}$ & $0.954^{* *}$ & 0.000 & -0.121 & 1 \\
\hline & $\mathrm{p}$ & 0.016 & 0.018 & 0.000 & 0.996 & 0.248 & \\
\hline \multirow{2}{*}{ TLF } & $\mathrm{r}$ & $0.524^{*}$ & $0.586^{* \prime}$ & 0.172 & $0.673^{*}$ & 1 & \\
\hline & $\mathrm{p}$ & 0.000 & 0.000 & 0.100 & 0.000 & & \\
\hline \multirow{2}{*}{$\mathrm{CNF}$} & $\mathrm{r}$ & $0.767^{* *}$ & $0.817^{* *}$ & 0.194 & 1 & & \\
\hline & $\mathrm{p}$ & 0.000 & 0.000 & 0.062 & & & \\
\hline \multirow{2}{*}{ DNF } & $\mathrm{r}$ & -0.094 & $0.409^{* *}$ & 1 & & & \\
\hline & $\mathrm{p}$ & 0.370 & 0.000 & & & & \\
\hline \multirow{2}{*}{ APDNF } & $\mathrm{r}$ & $0.358^{*}$ & 1 & & & & \\
\hline & $\mathrm{p}$ & 0.000 & & & & & \\
\hline \multirow{2}{*}{ TDNF } & $\mathrm{r}$ & 1 & & & & & \\
\hline & $\mathrm{p}$ & & & & & & \\
\hline \multicolumn{8}{|c|}{ Table 2. Correlation between All Measurements on the Femur } \\
\hline \multicolumn{8}{|c|}{$\begin{array}{l}* * \text { Correlation is significant at the } 0.01 \text { level }(2 \text { - tailed }) \\
* \text {. Correlation is significant at the } 0.05 \text { level }(2 \text { - tailed })\end{array}$} \\
\hline
\end{tabular}

\begin{tabular}{|ccccccc|}
\hline Number of & \multicolumn{2}{c}{ Right } & \multicolumn{1}{c|}{ Left } & Both \\
Nutrient Foramen & $\mathbf{N}$ & $\mathbf{\%}$ & $\mathbf{N}$ & $\mathbf{\%}$ & $\mathbf{N}$ & $\%$ \\
1 & 28 & 53.8 & 22 & 53.7 & 50 & 53.76 \\
2 & 23 & 44.2 & 18 & 43.9 & 41 & 44.09 \\
3 & 1 & 1.9 & 1 & 2.4 & 2 & 2.15 \\
Total & $\mathbf{5 2}$ & $\mathbf{1 0 0 . 0}$ & $\mathbf{4 1}$ & $\mathbf{1 0 0 . 0}$ & $\mathbf{1 0 0}$ & $\mathbf{1 0 0 . 0}$ \\
\hline Table 3. Number and Distribution of Nutrient Foramen \\
\hline
\end{tabular}

\begin{tabular}{|ccc|}
\hline Foraminal Index Type & $\mathbf{N}$ & $\%$ \\
1 & 8 & 8.6 \\
2 & 84 & 90.3 \\
3 & 1 & 1.1 \\
Total & 93 & 100 \\
\hline \multicolumn{2}{|c|}{ Table 4. Topographical Distribution of the Nutrient Foramina Based } \\
on the Foraminal Index of the Femur \\
\hline
\end{tabular}

A statistically significant negative correlation was found between the transverse diameter of the nutrient foramen and foraminal index $(\mathrm{r}=-0.249, \mathrm{P}<0.05)$. A statistically significant positive correlation was found between the anteroposterior diameter of the nutrient foramen and all other measurements $(r=0.245-0.817, \mathrm{P}<0.05)$. In addition, the highest statistically significant correlation was found between DNF and foraminal index $(r=0.954, \mathrm{P}<0.001)$. The number and distribution of nutrient foramen in the right and left femurs are shown in Table 3.

Most of the nutrient foramina were presented along with the middle third of the femur and the foraminal index ranging between $28.90 \%$ and $78.53 \%$ of the total bone length. Of the total 93 foramina, $84(90.3 \%)$ were in the middle third (Type 2), $8(8.6 \%)$ in the proximal third (Type 1$)$ and 1 (1.1\%) in the distal third (Type 3) (Table 4).
The comparison of the measurements related to the nutrient foramen with the studies conducted on different societies is shown in Table 5.

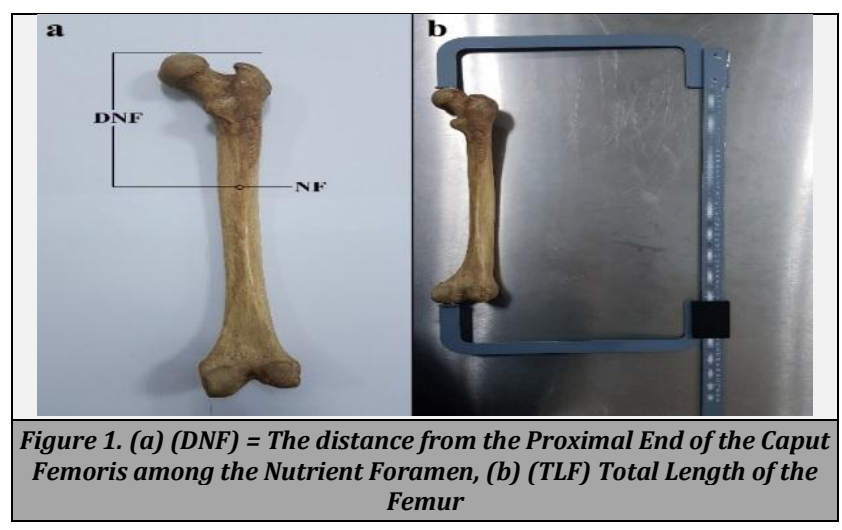

\section{DISCUSSION}

Nutrient foramina provide an opening shaft for the nutritional arteries. In this field previously many authors, have conducted studies on the differences in the location of nutrient foramina of various races. In the present study, the mean total lengths of all 93 femurs were obtained as $43.09 \pm$ $3.1 \mathrm{~cm}$ which is almost similar to the results obtained by Hamzehtofigh et al. $42.4 \mathrm{~cm}$, Kirschner et al. $40.8 \mathrm{~cm}$ in Germans and Bosnia and Herzegovina $44.34 \pm 2.5 \mathrm{~cm} \cdot 13,17,18$ The current femoral measurements were similar to $44.34 \mathrm{~cm}$ in blacks and $44.96 \mathrm{~cm}$ in white South Africans ${ }^{19}$ and also approximately $10 \%$ longer than $40.1 \mathrm{~cm}$ in Americans. ${ }^{20}$ In a study done by Krishna et al. ${ }^{21}$ it has been reported that the average length of the femur was $43.48 \mathrm{~cm}$ on the right side and $43.7 \mathrm{~cm}$ on the left side. In addition, the distance of the nutrient foramina to the upper end was $18.75 \pm 4.79 \mathrm{~cm}$ and $16.98 \pm 3.99 \mathrm{~cm}$ respectively. Collipal et al. ${ }^{22}$ observed the average length of the femur as $43.52 \mathrm{~cm}$ on the right side and $43.7 \mathrm{~cm}$ on the left side and the distance of the nutrient foramina to the upper end as $19.2 \pm 4.81 \mathrm{~cm}, 19.5 \pm 4.97 \mathrm{~cm}$ respectively. In a study done by Bichitrananda and Meena ${ }^{23}$ the mean length of the femur has been reported as $43.6 \mathrm{~cm}$. They also reported that the average distance of the nutrient foramen from the upper end was $15.25 \mathrm{~cm}$. In our study, the average length of femur supports the above previous studies (right side $42.77 \pm 2.9 \mathrm{~cm}$ and left side $43.50 \pm 3.25 \mathrm{~cm}$ ), and with the average distance of the nutrient foramina from the upper end as $17.73 \mathrm{~cm} \pm 3.64$ on the right side and $18.36 \mathrm{~cm}$ \pm 4.80 on the left side (Table 1 ).

The analysis revealed that 28 (53.8\%) of the femurs with a single nutrient foramen were on the right side and 22 (53.7 $\%$ ) were on the left side, respectively. In a study done by Mazengenya and Fasemore ${ }^{19}$ of adult black and white South Africans, they have been reported that majority of the femora in black South Africans had one nutrient foramen, followed by two on their surfaces. On the contrary, they also stated that situation was different in white South Africans where double nutrient foramina were the commonest followed by a single nutrient foramen. The results in our study were in agreement with reports from other studies, Shrestha et al. ${ }^{24}$, Longia et al. ${ }^{11}$ in Indians, Pereira et al. ${ }^{25}$ and Ranwaeera ${ }^{2}$, (58 
$\%)$ who reported that a single nutrient was the commonest on the shaft of the femur.

When we compare the findings of previous studies, Campos et al. ${ }^{26}$ (60\%), Prashanth et al. ${ }^{27}$ (44.2 \%), Poornima and Angadi ${ }^{28}$ (37\%), Bichitrananda and Meena ${ }^{23}$ (59.4\%) reported double nutrient foramina. The observation that about $40.9 \%$ of the bones have two NF is similar to that reported by previous studies. Unlike in our study, they did not separate the bones on the sides of the limbs they belonged to.

In our study, most of the foramen was single nutrient foramen. Dervisevic et al. ${ }^{18}$ has reported that the majority of two NF $57.1 \%$ on the right femur and $42.1 \%$ on the left femur. Similarly in our study, bones with two nutrient foramina were observed in 23 (44.2\%), 18 (43.9\%) on the right and left sides, respectively. (Table 3).

In our study, triple nutrient foramina were found 1(1.9 $\%)$ on right and $1(2.4 \%)$ on the left side of the femur in disagreement with Forriol Campos et al.26 who reported approximately $10 \%$ of the femur and Ranaweera et al. ${ }^{2}$ who reported $6 \%$. Prashanth et al. ${ }^{27}$ and who reported $3.5 \%$. In accordance with our study, Pereira et al. ${ }^{25}$ reported $1.28 \%$ of the femur with triple nutrient foramina. Although Sharma ${ }^{29}$ identified $2 \%$ and Prashanth et al. $4.6 \%$ femur with absent nutrient foramina in their study. ${ }^{22,23}$ In our findings we did not observe any femur with absent nutrient foramen. This finding is in accordance with Shrestha et al. ${ }^{24}$ and Pereira et al. ${ }^{25}$ who did not report any absent nutrient foramina in their study.

Position of Nutrient Foramina: In the present study, most of the nutrient foramina 84 (90.3\%) were found to be located along the middle third of the femur and the rest were in the proximal third, and in the distal third of the femur (Table 3). These results were in accordance with those of Dervisevic et al. ${ }^{18}$ (96.4 \%), Ranaweera et al. ${ }^{2}$ (85.19 \%), Murali Krishna et al.21 (73.11 \%), Gupta and Ambekar et al. ${ }^{30}$ (78.22 \%). However, these findings did not coincide with those of Hamzehtofigh et al. ${ }^{18}$ (72.15 \%) and Rashid et al. ${ }^{31}$ (61.18\%), Ferriol Campos et al. who has reported that the nutrient foramina were presented in the upper third of the femur.

Our study has shown that the foraminal index varies between $28.90 \%$ and $78.53 \%$. This shows that foramina formation can occur in any part of the bone, such as the proximal, middle or distal third of the bone. In addition, the results of this study are consistent with the previous studies by Vinay et al. ${ }^{32}$ Krishna et al. ${ }^{21}$ and Dervisevic et al. ${ }^{19}$ Gupta and Ambekar, ${ }^{27}$ the majority of foramina are located in the middle third of the femoral bone and have shown that it is a type II of a foraminal index.

Hamzehtofigh et al. ${ }^{17}$ examined the localization and number of nutrient foramina in 65 dry femoral bones of unknown age and gender belonging to the Iran population. They reported the anteroposterior diameter of the location of the nutrient foramen of femur as $41.8 \pm 32.2 \mathrm{~mm}$ and the transverse diameter of the location of the nutrient foramen of femur as $51.2 \pm 44.9 \mathrm{~mm}$. Whereas in our study the anteroposterior diameter of the nutrient foramen of the femur was $27.33 \pm 2.65 \mathrm{~mm}$ on right and $27.66 \pm 2.87 \mathrm{~mm}$ on the left side. In our study, the transverse diameter of NF of the femur was $17.73 \pm 3.64 \mathrm{~mm}$ on right and $18.36 \pm 4.80$ $\mathrm{mm}$ on left sides. In a study done by Collipal et al. ${ }^{22}$ the anteroposterior diameter was $27.7 \pm 3.6 \mathrm{~mm}$ on right and
$28.1 \pm 2.1 \mathrm{~mm}$ on the left side. They reported a transverse diameter of $27.4 \pm 2.3 \mathrm{~mm}$ on right and $27.1 \pm 4.8 \mathrm{~mm}$ on the left side. In our study, the transverse diameter of the nutrient foramen of the femur was in accordance with Collipal et al. ${ }^{22}$

The nutrient foramen underlines the significance of perforating arteries to provide the blood supply to the medullary wall and bone marrow. During surgical interventions, the nutrient artery area of the femur has to be handled with caution for subtrochanteric fractures to prevent haemorrhage. The nutrient artery may be involved in traumatic injuries, which make the location of nutrient foramen very important. The present study conducted on nutrient foramina of 93 femurs (52 right and 41 left sides) of dry adult human femora and has shown that most of the nutrient foramina are located in the middle third of the femur. In addition, double nutrient foramina were observed as a common finding in our study.

\section{CONCLUSIONS}

The findings of our study are consistent with the findings of previous studies on the number and location of the nutrient foramina in the femur. This study also provided important information on the clinical significance of nutrient foramina. During surgical procedures, it is very important to know the exact location and distribution of the nutrient foramina in the bone diaphysis and to avoid damaging the nutrient vessels. There is a need for larger-scale future research supported by larger sample sizes and radiographic studies.

\begin{tabular}{|c|c|c|c|c|c|}
\hline $\begin{array}{l}\text { Researcher } \\
\text { (Year) }\end{array}$ & Population & $\mathbf{N}$ & Type 1 & Type 2 & Type 3 \\
\hline $\begin{array}{l}\text { Rashid et al. } \\
\text { (2019) }\end{array}$ & India & 85 & $52(61.18 \%)$ & $31(36.47 \%)$ & $2(2.35 \%)$ \\
\hline $\begin{array}{c}\text { Gupta \& Ambekar } \\
(2016)\end{array}$ & Nepal & 124 & $26(20.97 \%)$ & 97 (78.22 \%) & $1(0.81 \%)$ \\
\hline $\begin{array}{c}\text { Dervisevic et al. } \\
\text { (2019) }\end{array}$ & $\begin{array}{c}\text { Bosnia \& } \\
\text { Herzegovina }\end{array}$ & 47 & $3(6.38 \%)$ & $44(93.62 \%)$ & $0(0 \%)$ \\
\hline $\begin{array}{c}\text { Ranaweera et al. } \\
(2020)\end{array}$ & Sri Lanka & 81 & $12(14.81 \%)$ & $69(85.19 \%)$ & $0(0 \%)$ \\
\hline $\begin{array}{c}\text { Hamzehtofigh et al. } \\
\text { (2018) }\end{array}$ & Iran & 172 & $8(4.65 \%)$ & $80(46.51 \%)$ & $84(48.84 \%)$ \\
\hline This study (2020) & Turkey & 93 & $8(8.6 \%)$ & $84(90.3 \%)$ & $1(1.1 \%)$ \\
\hline
\end{tabular}

Data sharing statement provided by the authors is available with the full text of this article at jemds.com.

Financial or other competing interests: None.

Disclosure forms provided by the authors are available with the full text of this article at jemds.com.

\section{REFERENCES}

[1] Standing S. Gray's anatomy: the anatomical basis of clinical practice. $41^{\text {th }}$ edn. Elsevier 2016.

[2] Ranaweera L, Perera PI, Pathiraja PP, et al. Estudio de las variaciones morfológicas y morfométricas de los forámenes nutricios diafisarios de fémur en Sri Lanka. Int J Morphol 2020;38(5):1311-6.

[3] Sevitt S, Thompson RG. The distribution and anastomoses of arteries supplying the head and neck of the femur. J Bone Joint Surg Br 1965;47:560-73. 
[4] Shapiro F. Bone development and its relation to fracture repair. The role of mesenchymal osteoblasts and surface osteoblasts. Eur Cell Mater 2008;15:53-76.

[5] Moore K, Dalley A, Agur A. Clinically oriented anatomy. $6^{\text {th }}$ edn. Philadelphia: Lippincott Williams \& Wilkins 2010.

[6] Sinha P, Mishra SR, Kumar P, et al. Morphology and topography of nutrient foramina in fibula. Annals of International Medical and Dental Research 2016;2(6):712.

[7] Ukoha UU, Umeasalugo KE, Nzeako HC, et al. A study of nutrient foramina in long bones of Nigerians. Natl J Med Res 2013;3(4):304-8.

[8] Bilodi AKS, Reddy BS. A study on nutrient foramina of fibula, its medicolegal aspect and clinical importance in dentistry. World J Pharm Pharm Sci 2014;3(2):2133-44.

[9] Bhat D. Study of nutrient foramina of adult femora with its correlation to length of the bone. Int J Anat Res 2015;3(4):1573-7.

[10] Mysorekar VR. Diaphysial nutrient foramina in human long bones. J Anat 1967;101(Pt 4):813-22.

[11] Longia GS, Ajmani ML, Saxena SK, et al. Study of diaphyseal nutrient foramina in human long bones. Acta Anat (Basel) 1980;107(4):399-406.

[12] Skawina A, Wyczolkowski, M. Nutrient foramina of humerus, radius and ulna in human fetuses. Folia Morphol 1987;46(1-2):17-24.

[13] Kirschner MH, Menck J, Hennerbichler A, et al. Importance of arterial blood supply to the femur and tibia for transplantation of vascularized femoral diaphyses and knee joints. World J Surg 1998;22 (8):84551.

[14] Rao VS, Kothapalli J. The diaphyseal nutrient foramina architecture - a study on the human upper and lower limb long bones. Int J Pharm Bio Sci 2014;9(1):36-41.

[15] Singh AK, Kumari R. Evaluation of nutrient foramina of the dry adult human femur bone of north Indian population. Acad Anat Int 2019;5(2):18-21.

[16] Hughes $H$. The factors determining the direction of the canal for the nutrient artery in the long bones of mammals and birds. Acta Anat (Basel) 1952;15(3):26180.

[17] Hamzehtofigh M, Rahimi M, Bayat, P. Evaluation of nutrient foramen of the femur, tibia, and fibula bones in center of Iran. Iranian J Orthop Surg 2018;16(2):238-43.

[18] Dervisevic L, Dervisevic A, Ajanovic Z, et al. Analytical and morphometric study of nutrient foramina of femur and its clinical implications. Int J Res Med Sci 2019;7(4):1324-9.

[19] Mazengenya P, Fasemore MD. Morphometric studies of the nutrient foramen in lower limb long bones of adult black and white South Africans. Eur J Anat 2015;19(2):155-63.

[20] Nagel A. The clinical significance of the nutrient artery. Orthop 1993;22(5):557-61.

[21] Krishna SM, Kumar PU, Sirisha V, et al. Morphologic and morphometric study of the nutrient foramina in dry human femur bones of Telangana region. Int J Anat Res 2016;4(2):2464-8.

[22] Collipal E, Vargas R, Parra X, et al. Diaphyseal nutrient foramina in the femur, tibia and fibula bones. Int J Morphol 2007;25(2):305-8.

[23] Roul B, Goyal M. A study of nutrient foramen in long bones of inferior extremity in human being. Int J Adv Res 2015;3(4):945-8.

[24] Shrestha P, Mansur DI, Mehta DK, et al. Variations of nutrient foramen of femur and its clinical implications. J Lumbini Med Coll 2019;7(2):61-4.

[25] Pereira GAM, Lopes PTC, Santos AMPV, et al. Nutrient foramina in the upper and lower limb long bones: morphometric study in bones of Southern Brazilian adults. Int J Morphol 2011;29(2):514-20.

[26] Campos FF, Pellico LG, Alias MG, et al. A study of the nutrient foramina in human long bones. Surg Radiol Anat 1987;9(3):251-5.

[27] Prashanth KU, Murlimanju BV, Prabhu LV, et al Morphological and topographical anatomy of nutrient foramina in the lower limb long bones and its clinical importance. Australas Med J 2011;4(10):530-7.

[28] Poornima B, Angadi AV. A study of nutrient foramina of the dry adult human femur bones. International Journal of Biomedical Research 2015;6(6):370-3.

[29] Sharma M, Sharma T, Wadhwa A, et al. Morphological variations of nutrient foramina in lower limb long bones. Int J Med Dent Sci 2015;4(2):802-8.

[30] Gupta AK, Ambekar MN. Study of nutrient foramina in adult human femur bones. J Nepalgunj Med Coll 2016;14(2):44-9.

[31] Rashid S, Ahmad T, Gul S, et al. Anatomical study of nutrient foramina in adult human femur bones. Int J Anat Res 2019;7(1.3):6280-2.

[32] Vinay G, Gowri SRM. Anatomical study of the nutrient foramen of lower limb long bones in South Indian population. Indian J Clin Anat Physiol 2017;4(2):222-4. 